\title{
Platinum dissolution and ethanol oxidation reaction on Pt-activated nickel foam in sodium hydroxide solution
}

\author{
Boguslaw Pierozynski*, Tomasz Mikolajczyk \\ University of Warmia and Mazury in Olsztyn, Department of Chemistry, Faculty of Environmental Management and \\ Agriculture, Plac Lodzki 4, 10-727 Olsztyn, Poland \\ "Corresponding author: e-mail: boguslaw.pierozynski@uwm.edu.pl
}

\begin{abstract}
Electrochemical oxidation of ethanol becomes an important process of modern electrochemistry, due to its potential application into direct ethanol fuel cell technology. As rates of ethanol oxidation reaction (EOR) are significantly enhanced in alkaline media, employment of highly corrosion resistant under alkaline conditions, but non-noble metals becomes of superior practical importance. This communication article reports on the process of anodic dissolution of platinum, which is investigated on Pt activated, electrooxidized nickel foam electrodes, employed for ethanol oxidation reaction in $0.1 \mathrm{M}$ sodium hydroxide solution. The above was revealed through the application of cyclic voltammetry and combined SEM/EDX (scanning electron microscopy and energy dispersive $\mathrm{x}$-ray) spectroscopy examinations.
\end{abstract}

Keywords: Pt-activated nickel foam, ethanol oxidation reaction, Pt-dissolution.

\section{INTRODUCTION}

The catalytic process of ethanol electro-oxidation brings significant attention, due to its potential application into energy conversion technologies, i.e. direct ethanol fuel cell $(\mathrm{DEFC})^{\mathbf{1}, 2}$. As kinetics of ethanol oxidation reaction (EOR) are radically enhanced in basic environments, application of non-noble, but highly stable metals under alkaline conditions (e.g. 3d nickel structures) becomes of significant importance from a technological point of view $^{3-5}$. Furthermore, nickel could specifically be catalysed towards the EOR through the surface formation of extended oxide/hydroxide layer ${ }^{2,6-8}$ supplemented by electro(chemical) deposition of nanoparticles of noble metals, such as $\mathrm{Pt}^{3,9-11}$.

Phenomena of anodic oxidation and dissolution of platinum in acidic and alkaline media have recently been studied in works by Topalov et al. ${ }^{12}$ and Cherevko et al. ${ }^{13}$, and earlier by Zolfaghari and Conway ${ }^{14}$. In this communication, we report on anodic dissolution of platinum occurred upon extended electrooxidation of Pt-modified nickel foam electrodes in $0.1 \mathrm{M} \mathrm{NaOH}$ solution, in relation to ethanol oxidation reaction.

\section{EXPERIMENTAL}

Working electrodes were prepared from MTI nickel foam samples in several stages. Starting from acetone wash (15 min + ultrasonication) of freshly cut foam samples, the process involved air drying and acid etching in $2 \mathrm{M} \mathrm{HCl}\left(15 \mathrm{~min}\right.$ at $\left.60^{\circ} \mathrm{C}\right)$. Then, Pt-modified $\mathrm{Ni}$ foam composite electrodes were produced through spontaneous deposition of platinum, carried-out in 0.005 $\mathrm{M}$ chloroplatinic acid hexahydrate: CPAH. Atmospheric oxygen was removed from solution before each electrochemical experiment through bubbling with high-purity argon (Ar 6.0 grade, Linde). Furthermore, the argon gas flow was kept above the solution upon all electrochemical measurements. All additional details on the preparation of electrodes (reference and counter), electrochemical cell and electrolyte solutions employed for the purpose of this work were comprehensively discussed in recent works from this laboratory (see Refs. 15 and 16). Combined electrochemical (cyclic voltammetry) and spectroscopic (SEM/EDX) examinations were employed in this work. All electrochemical measurements were performed at room temperature by means of Solartron 12,608 W Full Electrochemical System (with employment of Corrware/ Corrview 2.9 software packages), whereas spectroscopic characterization of Pt-based Ni foam samples was conducted by means of JEOL JSM-7600 F/X-Max SDD Oxford Inca 250 integrated SEM/EDX unit (see details in Ref. 16).

\section{RESULTS AND DISCUSSION}

Figures 1a and $1 \mathrm{~b}$ below show cyclic voltammograms for electrooxidation of Pt-modified Ni foam electrode (carried-out in $0.1 \mathrm{M} \mathrm{NaOH}$ ) and ethanol electrooxidation performed on such pre-treated foam electrodes in the presence of $0.5 \mathrm{M} \mathrm{C}_{2} \mathrm{H}_{5} \mathrm{OH}$ in $0.1 \mathrm{M} \mathrm{NaOH}$ supporting electrolyte, correspondingly. Hence, a major, broad cathodic feature (peak A) that is observed in Figure 1a corresponds to the reduction of $\mathrm{Ni}(\mathrm{II})$ oxidation products, generated upon continuous cycling over the potential exceeding $1.5 \mathrm{~V} / \mathrm{RHE}^{17}$. Then, when suchpretreated Pt-activated Ni foam electrodes are exposed to the process of ethanol oxidation (see Fig. 1b), it is clear that the EOR behaviour is significantly dependent on the employed electrode pre-treatment procedure. In other words, superior facilitation of the EOR was obtained when the surface pre-treatment involved 100 voltammetric cycles conducted at a sweep-rate of 200 $\mathrm{mV} \mathrm{s}^{-1}$ over the potential range $0.05-1.90 \mathrm{~V}$ vs. RHE. Conversely, the least favourable EOR behaviour was recorded on the nickel foam electrode prepared under most severe experimental conditions, i.e. with employment of $500 \mathrm{CV}$ sweeps at a scan-rate of $500 \mathrm{mV} \mathrm{s}^{-1}$ (see Fig. 1b again).

It is well-known that extended surface-electrooxidation of nickel ${ }^{2,6-8}$ enhances its EOR catalytic properties. However, platinum was found to undergo significant dissolution over the potential range characteristic of oxide formation and oxygen evolution reaction ${ }^{12}{ }^{13}$, where $\mathrm{Pt}$ oxidation and dissolution onsets in $0.05 \mathrm{M} \mathrm{NaOH}$ solu- 


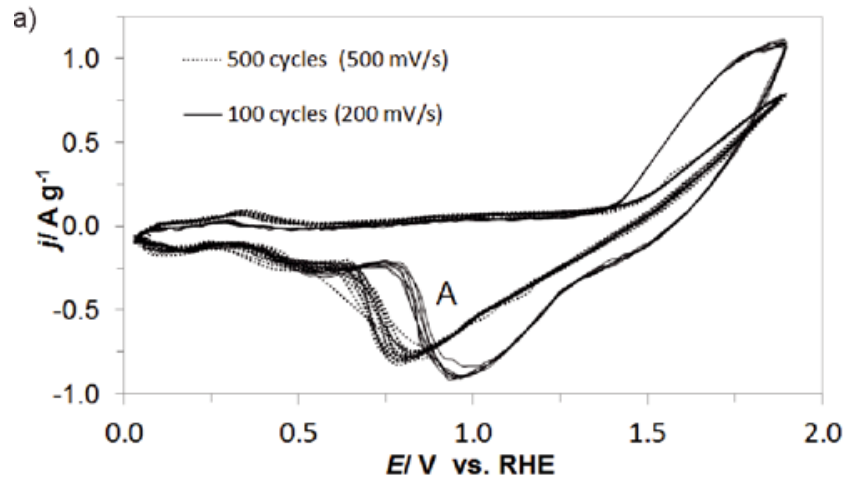

b)

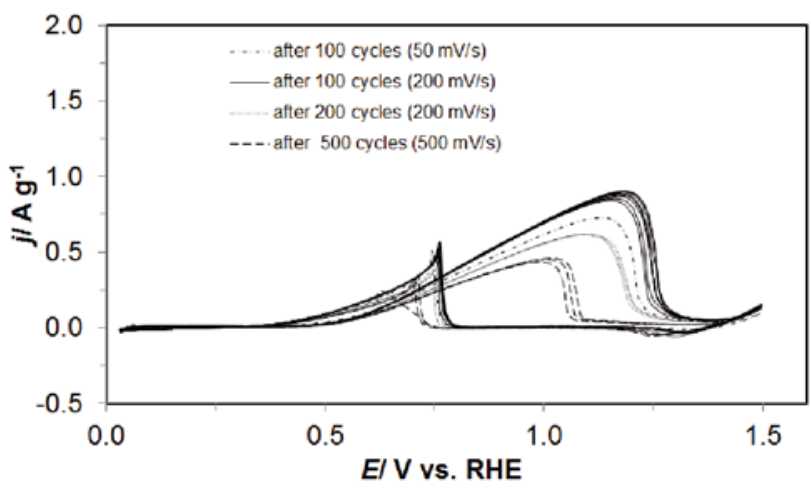

Figure 1. a) Examples of cyclic voltammograms for electrooxidation of Pt-modified Ni foam electrode, carried-out in $0.1 \mathrm{M} \mathrm{NaOH}$ (number of performed cycles and sweep-rates indicated); b) Cyclic voltammograms for ethanol electrooxidation carried-out in 0.1 $\mathrm{M} \mathrm{NaOH}$ in the presence of $0.5 \mathrm{M} \mathrm{C}_{2} \mathrm{H}_{5} \mathrm{OH}$ on pre-electrooxidized (in $0.1 \mathrm{M} \mathrm{NaOH}$ solution) $\mathrm{Pt}$ modified $\mathrm{Ni}$ foam electrodes (employed sweep-rate: $50 \mathrm{mV} \mathrm{s}^{-1}$ )

tion already commence ${ }^{13}$ around the potential values of 0.75 and $1.00 \mathrm{~V}$ vs. RHE, correspondingly.

In this communication, the process of surface oxidation along with a Pt dissolution effect could clearly be observed in Figures 2 and 3, and Table 1 below. Thus, Figures $2 \mathrm{a}$ and $2 \mathrm{~b}$ present SEM micrograph picture and EDX pattern of Pt-modified nickel foam electrode (at $100.000 \times$ magnification), electrooxidized under moderate conditions (100 voltammetric cycles over the potential range $0.05-1.90 \mathrm{~V} / \mathrm{RHE}$ in $0.1 \mathrm{M} \mathrm{NaOH}$ at a sweep-rate of $50 \mathrm{mV} \mathrm{s}^{-1}$ ). Then, imposition of an extensive surface oxidation treatment on the Pt-modified $\mathrm{Ni}$ foam sample (500 cycles over the potential range $0.05-1.90 \mathrm{~V}$ in 0.1 $\mathrm{M} \mathrm{NaOH}$ at a sweep-rate of $500 \mathrm{mV} \mathrm{s}^{-1}$ ) qualitatively (a)
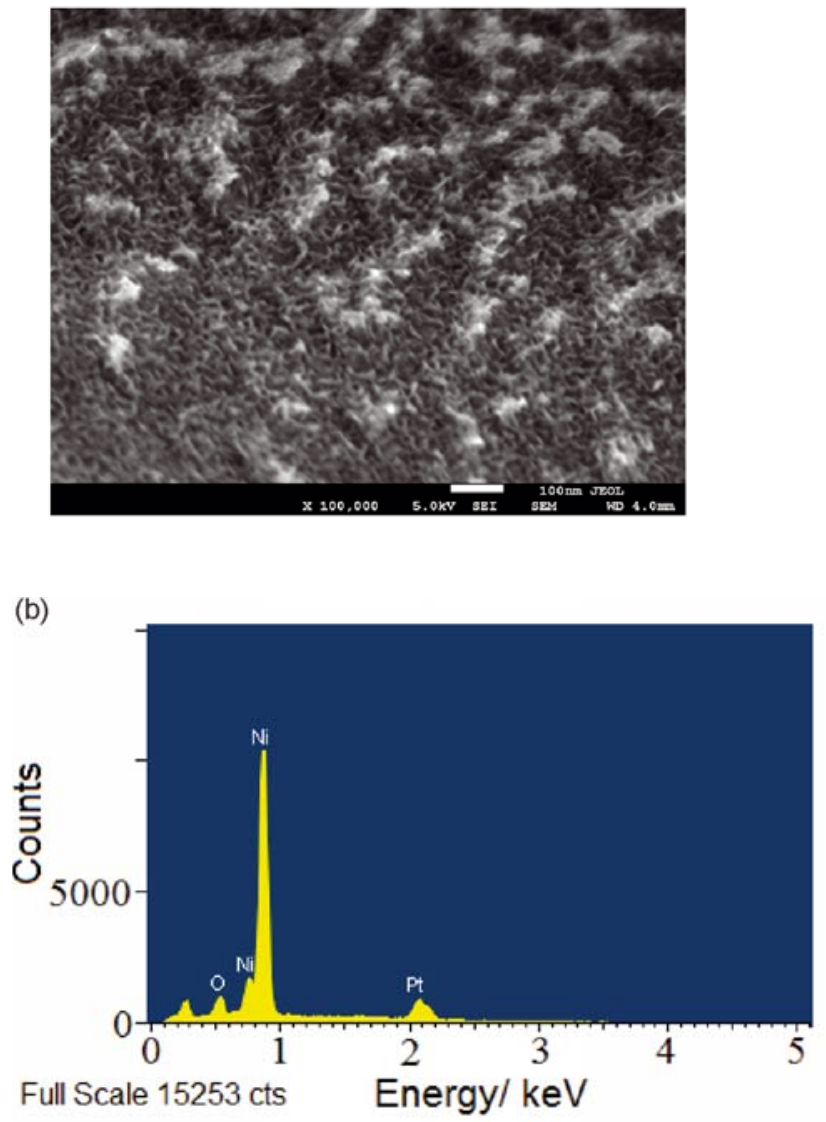

Figure 2. a) SEM micrograph picture of surface electrooxidized (100 cycles over the potential range $0.05-1.90 \mathrm{~V} /$ RHE in $0.1 \mathrm{M} \mathrm{NaOH}$ at a sweep-rate of $50 \mathrm{mV}$ $\mathrm{s}^{-1}$ ) Pt-modified Ni foam electrode (ca. $0.2 \mathrm{wt} \% \mathrm{Pt}$ ), taken at $100.000 \times$ magnification with an acceleration voltage of $5.0 \mathrm{kV}$; b) As above, but EDX spectrum

resulted in significant surface roughening (see Figure 3a) along with an increase of oxygen level and depletion of platinum intensity in the EDX spectrum (compare Fig. 2b with Fig. 3b). These results could strongly be supported by the EDX-derived numerical data shown in Table 1. In short, it could qualitatively be concluded that more extensive surface oxidation treatments result in a substantial loss of deposited $\mathrm{Pt}$ particles along with increased oxygen level (specifically, compare the results obtained for Sample 1 with those of Sample 3 and Sample 4 in Table 1).

Table 1. EDX-derived surface composition for electrooxidized Pt-modified Ni foam samples

\begin{tabular}{|c|c|c|c|c|c|}
\hline Element & Measurement & Sample 1 & Sample 2 & Sample 3 & Sample 4 \\
\hline \multirow{3}{*}{$\mathrm{Pt} / \%$} & 1 & 18.59 & 9.42 & 4.95 & 4.56 \\
\hline & 2 & 19.09 & 9.51 & 8.85 & 5.23 \\
\hline & 3 & 13.74 & 7.66 & 7.88 & 3.67 \\
\hline \multirow{3}{*}{$\mathrm{Ni} / \%$} & 1 & 79.25 & 88.21 & 92.01 & 90.58 \\
\hline & 2 & 78.71 & 88.53 & 88.19 & 89.40 \\
\hline & 3 & 83.80 & 90.19 & 85.25 & 92.42 \\
\hline \multirow{3}{*}{$\mathrm{O} / \%$} & 1 & 2.16 & 2.36 & 3.04 & 4.85 \\
\hline & 2 & 2.21 & 1.96 & 2.96 & 5.37 \\
\hline & 3 & 2.46 & 2.16 & 6.87 & 3.91 \\
\hline
\end{tabular}

Sample 1: 100 cycles, 0.05-1.90 V/RHE, $50 \mathrm{mV} \mathrm{s}^{-1}$

Sample 2: 100 cycles, $0.05-1.90 \mathrm{~V} / \mathrm{RHE}, 200 \mathrm{mV} \mathrm{s}^{-1}$

Sample 3: 200 cycles, $0.05-1.90 \mathrm{~V} / \mathrm{RHE}, 200 \mathrm{mV} \mathrm{s}^{-1}$

Sample 4: 500 cycles, $0.05-1.90 \mathrm{~V} / \mathrm{RHE}, 500 \mathrm{mV} \mathrm{s}^{-1}$ 
(a)

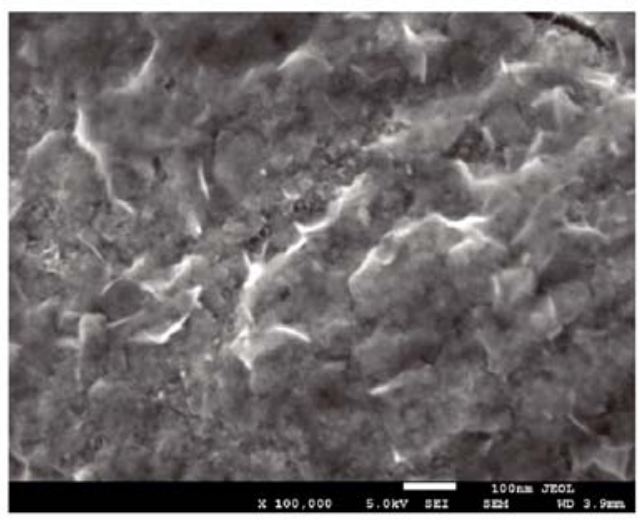

(b)

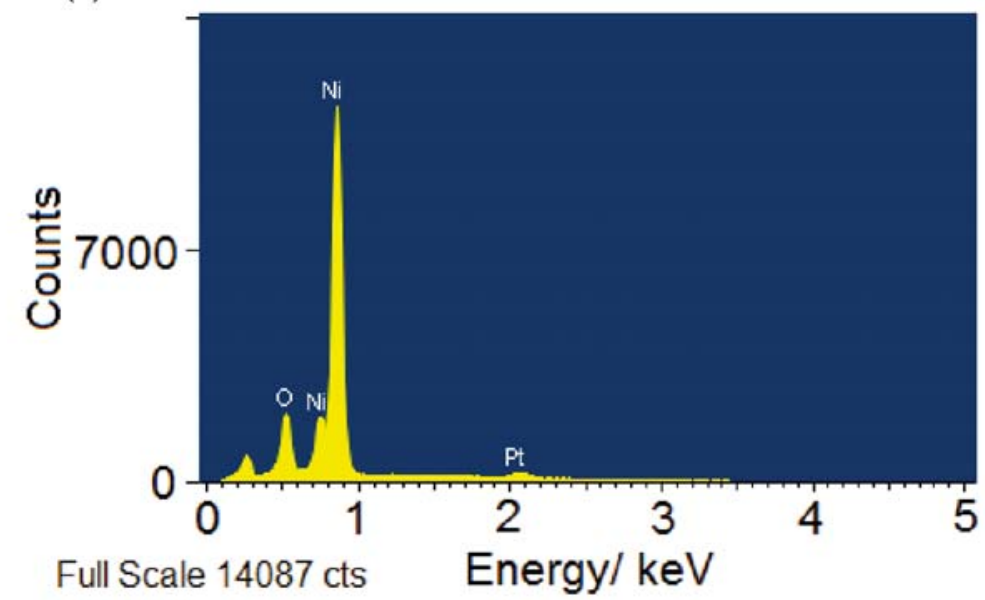

Figure 3. a) SEM micrograph picture of surface electrooxidized (500 cycles over the potential range $0.05-1.90 \mathrm{~V} / \mathrm{RHE}$ in $0.1 \mathrm{M}$ $\mathrm{NaOH}$ at a sweep-rate of $500 \mathrm{mV} \mathrm{s}^{-1}$ ) Pt-modified $\mathrm{Ni}$ foam electrode (ca. $0.2 \mathrm{wt} \% \mathrm{Pt}$ ), taken at $100.000 \times$ magnification with an acceleration voltage of $5 \mathrm{kV}$; b) As above, but EDX spectrum

\section{CONCLUSION}

Pt-modified ( $c a .0 .2$ wt. \% Pt), electrooxidized nickel foam electrodes are catalytic towards ethanol oxidation in $0.1 \mathrm{M} \mathrm{NaOH}$ supporting electrolyte. Although formation of nickel oxide/hydroxide layer is essential for nickel to exhibit catalytic properties towards ethanol electrooxidation, extended surface oxidation of Pt-activated Ni foam leads to simultaneous Pt oxidation and dissolution phenomena. Therefore, fabrication of Pt-modified, inherently EOR active nickel foam anode requires that a special optimization procedure be employed with respect to the process of voltammetric development of surface oxides.

In fact, the latter would mean effective securing of $\mathrm{Pt}$ sites from their dissolution upon oxide formation, which could be achieved e.g. by preferential in situ surface reversible adsorption of some organic molecule(s). This aspect will be studied in detail in another work, with an intention to produce electroactive, Pt-modified Ni foam electrode, for general use in electrocatalysis.

\section{LITERTURE CITED}

1. Song, S.Q., Zhou, W.J., Zhou, Z.H., Jiang, L.H., Sun, G.Q., Xin, Q., Leontidis, V., Kontou, S. \& Tsiakaras, P. (2005). Direct ethanol PEM fuel cells: The case of platinum based anodes. Int. J. Hydrogen Energy 30, 995-1001. DOI: 10.1016/j. ijhydene.2004.11.006.

2. Barbosa, A.F.B., Oliveira, V.L., van Drunen, J. \& Tremiliosi-Filho, G. (2015). Ethanol electro-oxidation reaction using a polycrystalline nickel electrode in alkaline media: Temperature influence and reaction mechanism. J. Electroanal. Chem. 746, 31-38. DOI: 10.1016/j.jelechem.2015.03.024.

3. Pierozynski, B. (2012). On the Ethanol electrooxidation reaction on catalytic surfaces of $\mathrm{Pt}$ in $0.1 \mathrm{M} \mathrm{NaOH}$. Int. J. Electrochem. Sci. 7, 4261-4271.

4. Dutta, A., Mahapatra, S.S. \& Datta, J. (2011). High performance PtPdAu nano-catalyst for ethanol oxidation in alkaline media for fuel cell applications. Int. J. Hydrogen Energy 36, 14898-14906. DOI: 10.1016/j.ijhydene.2011.02.101.

5. Dominguez-Crespo, M.A., Torres-Huerta, A.M., Brachetti-Sibaja, B. \& Flores-Vela, A. (2011). Electrochemical performance of $\mathrm{Ni}-\mathrm{RE}(\mathrm{RE}=$ rare earth $)$ as electrode material for hydrogen evolution reaction in alkaline medium. Int. J. Hydrogen Energy 36, 135-151. DOI: 10.1016/j.ijhydene.2010.09.064.

6. Motheo, A.J., Machado, S.A.S., Rabelo, F.J.B. \& Santos Jr., J.R. (1994). Electrochemical study of ethanol oxidation on nickel in alkaline media. J. Braz. Chem. Soc. 5, 161-165. DOI: 10.5935/0103-5053.19940028.

7. Kim, J.W. \& Park, S.M. (2005). Electrochemical oxidation of ethanol at nickel hydroxide electrodes in alkaline media studied by electrochemical impedance spectroscopy. J. Korean Electrochem. Soc. 8, 117-124. DOI: 10.5229/JKES.2005.8.3.117.

8. van Drunen, J., Napporn, T.W., Kokoh, B. \& Jerkiewicz, G. (2014). Electrochemical oxidation of isopropanol using a nickel foam electrode. J. Electroanal. Chem. 716, 120-128. DOI: 10.1016/j.jelechem.2013.08.003.

9. Gomes, J.F., Busson, B., Tadjeddine, A. \& Tremiliosi-Filho, G. (2008). Ethanol electro-oxidation over Pt(h k 1): Comparative study on the reaction intermediates probed by FTIR and SFG spectroscopies. Electrochim. Acta 53, 6899-6905. DOI: 10.1016/j.electacta.2008.01.054.

10. Abd-El-Latif, A.A., Mostafa, E., Huxter, S., Attard, G. \& Baltruschat, H. (2010). Electrooxidation of ethanol at polycrystalline and platinum stepped single crystals: A study by differential electrochemical mass spectrometry. Electrochim. Acta 55, 7951-7960. DOI: 10.1016/j.electacta.2010.04.008.

11. Pierozynski, B. (2012). Kinetic aspects of ethanol electrooxidation on catalytic surfaces of $\mathrm{Pt}$ in $0.5 \mathrm{M} \mathrm{H}_{2} \mathrm{SO}_{4}$. Int. J. Electrochem. Sci. 7, 3327-3338.

12. Topalov, A.A., Cherevko, S., Zeradjanin, A.R., Meier, J.C., Katsounaros, I. \& Mayrhofer, K.J.J. (2014). Towards a comprehensive understanding of platinum dissolution in acidic media. Chem. Sci. 5, 631-638. DOI: 10.1039/C3SC52411F.

13. Cherevko, S., Zeradjanin, A.R., Keeley, G.P. \& Mayrhofer, K.J.J. (2014). A comparative study on gold and platinum dissolution in acidic and alkaline media. J. Electrochem. Soc. 161(12), H822-H830. DOI: 10.1149/2.0881412jes.

14. Zolfaghari, A. \& Conway, B.E. (2000) Electroless deposition of $\mathrm{Pt}$ at a $\mathrm{Pd}$ electrode by reaction with sorbed $\mathrm{H}$ in $\mathrm{Pd} / \mathrm{H}$. J. Electroanal. Chem. 488, 151-153. DOI: 10.1016/ S0022-0728(00)00161-3.

15. Pierozynski, B., Mikolajczyk, T. \& Turemko, M. (2015). On the temperature performance of ethanol oxidation reaction at palladium-activated nickel foam. Electrocatalysis 6, 173-178. DOI: $10.1007 / \mathrm{s} 12678-014-0231-0$.

16. Pierozynski, B. \& Mikolajczyk, T. (2016). Cathodic evolution of hydrogen on platinum-modified nickel foam catalyst. Electrocatalysis 7, 121-126. DOI: 10.1007/s12678-015-0290-x.

17. Grdeń, M. \& Czerwiński, A. (2008). EQCM studies on $\mathrm{Pd}-\mathrm{Ni}$ alloy oxidation in basic solution. J. Solid State Electrochem. 12, 375-385. DOI: 10.1007/s10008-007-0452-8. 